M. Grandidier gains the Savigny prize for researches on the fauna of Zanzibar and Madagascar; while the Thorel prize is awarded both to M. Vayssières and M. Joly, for observations proving a small animal found in streams to be the larva of an insect of the family of Ephemerans.

The Montyon prize for statistics goes to Dr. Ricoux for his "Figured Demography of Algeria."

We further note that $M$. Birckel receives I 500 francs on the Montyon foundation, for an improvement in the Davy lamp, and that M. Dupuis receives the Delaland-Guerineau prize for his explorations in Tonkin.

The published list of subjects for prize competition in $\mathbf{1 8 8} \mathbf{r}$, 1882,1883 , and 1885 comprises the following subjects (briefly stated) among others :-Motor for tramways; physiology of champignons; influence of environment on plant-organs ; structure and development of cork ; internal organisation of European edriophthalmate crustaceans ; cure of Asiatic"cholera; genitourinary organs; revision of the theory of Jupiter's satellites; elasticity of crystalline bodies; origin of atmospheric electricity, and causes of electric phenomena in thunderstorms; inoculation as a prophylactic for domestic animals; coloured parts of the tegumentary system of animals, and fecundating matter of animated beings; marine, lacustrine, and terrestrial deposits on the French coast since the Roman epoch; botany of the North of France; diagnostic signs of death and prevention of premature burial.

\section{MEASURING THE INDEX OF REFRACTION OF EBONITE 1}

PROF. BELL found that when an intermittent beam of light fell on a sensitive selenium cell the sound produced in a telephone (which with a battery was attached to the selenium) was not entirely destroyed by interposing a thin sheet of eb nite in the path of the intermittent rays of light, or, in other words, that ebonite was slightly transparent for invisible rays that affected selenium. It occurred to us some months ago that if such invisible rays were at all of the nature of light, they probably suffered retardation in passing through the ebonite, or that refraction would take place if the sheet of ebonite were replaced by an ebonite prism or lens, a result we have been able experi mentally to confirm, and at the same time to measure the index of refraction.

$\mathrm{A} \mathrm{B}$ is a glass lens concentrating a parallel beam coming from a lime-light on to one hole $\mathrm{H}$ in a rapidly revolving brass disk CD. This disk we have constructed many times as thick as the

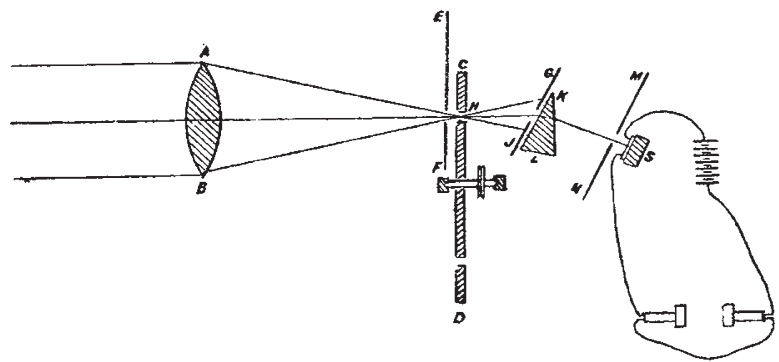

one employed by Prof. Bell, and have thus succeeded in eliminat ing all the sound produced by the syren action of the disk, so disturbing in delicate experiments. $E F$ is a stationary zine screen with a hole in it smaller than the holes in the rotating disk.

I. We first tried to focus these intermittent rays on a selenium cell by means of an ebonite lens, and so determine the focal length of the lens; but as our lens was then not mounted on an optical bench, so as to be moved parallel to itself, or rotated through known angles, and as the rays were invisible, so that our eyes could not of course guide us as to the proper position in which to put the lens, we failed to succeed in this very delicate experiment, which however our subsequent experiments, now to be described, show must ultimately succeed with the lens properly mounted.

2. A small portion of the intermittent light which passed through the hole $\mathrm{H}$ in the rotatory disk was allowed to fall on an ebonite prism $\mathrm{K} \mathrm{L}$, by passing through a slit in a zinc screen

${ }^{1}$ Note communicated to the Royal Society by Professors Ayrton and Perry.
G J, the slit being arranged parallel to the edge of the ebonite prism. The prism employed had an angle of $27^{\circ} \cdot 5 . \mathrm{MN}$ is another zinc screen with a slit in it also parallel to the edge of the prism, and placed in front of a sensitive selenium cell s (the cell described by us in the account of our experiments on "Seeing by Electricity"). This screen $M N$ was moved parallel to itself, while an experimenter listened with a telephone to each ear, and who was placed in another room, so as not to be influenced by seeing what changes were being made in the position of the screen or in the position of the ebonite prism. The telephones had each a resistance of $74 \mathrm{ohms}$, and the battery an electromotive force of about 40 volts. No direct light falling on the selenium, the listener at the telephones heard nothing for the majority of positions of the screen $\mathrm{M} \mathrm{N}$, but in one position represented in the figure a faint distant sound was distinctly heard, which was entirely cut off by interposing the hand in front of the selenium, or by moving away the prism.

The invisible rays that affect selenium after passing through ebonite are consequently refracted, and some preliminary experiments, when the ebonite prism was arranged for minimum devia tion, gave $x^{\prime} \mathrm{H}$ as a first rough approximation for the index of refiaction of these rays by ebonite. It is interesting to notice that the square, 2.89 , of this index of refraction is between the highest and lowest limits obtained by different experimenters for the specific inductive capacity of ebonite, so far agreeing with Maxwell's electromagnetic theory of light.

We are now having prisms of ebonite and of other opaque substances of different angles mounted on a goniometer stand, to enable us to measure the indices of refraction accurately.

\section{MOLECULAR ELECTROMAGNETIC INDUCTION ${ }^{1}$}

THE induction-currents balance which $I$ had the honour of bringing before the notice of the Royal Society (Proc. Roy. Soc. vol. xxix. p. 56) showed how extremely sensitive it was to the slightest molecular change in the composition of any metal or alloy, and it gave strong evidence of a pesuliarity in iron and steel which its magnetic properties alone failed to account for. We could with all non-magnetic metals easily obtain a perfect balance of force by an equivalent piece of the same metal, but in the case of iron, steel, and nickel it was with extreme difficulty that I could obtain a near approach to a perfect zero. Two pieces of iron cut off the same bar or wire, possessing the same magnetic moment, never gave identical results ; the difficulty consisted, that not withstanding each bar or wire could be easily made to produce the same inductive reaction, the time during which this reaction took place varied in each bar ; and although I could easily change its balancing power as regards inductive f rrce by a change in the mass of the metal, by heat or magnetism, the zero obtained was never equal to that obtained from copper or silver.

This led me to suppose the existence of a peculiarity in mag. netic metals which could not be accounted for except upon the hypothesis that there was a cause, then unknown, to produce the invariable effect.

Finding that it would be impossible to arrive at the true cause without some new method of investigation, which should allow me to observe the effects from an electrical circuit, whose active portion should be the iron wire itself, I constructed an appa. ratus or electro-magnetic induction balance, consisting of a single coil reacting upon an iron wire in its axis, and perpendicular to the coil itself; by this means the iron or other wire itself became a primary or secondary, according as the current passed through the coil or wire. Now with this apparatus we could induce secondary currents upon the wire or coil, if the coil was at any angle, except when the wire was absolutely perpendicular; in this state we could only obtain a current from some disturbing cause, and the current so obtained was no longer secondary but tertiary.

The whole apparatus however is more complicated than the general idea given above, as it was requi iite not only to produce effects, but to be able to app:eciate the direction of the electrical current obtained, and have coinparative measures of their value. In order to fully understand the mode of experiments, as well as the results obtained, I will first describe the apparatus employed.

The electro-magnetic induction balance consists-(I) of an

${ }^{x}$ Paper read at the Royal Society, March $\tau_{7}$, by Prof. D. E. Hughes, F.R.S. 